\title{
The influence of personality and weaning method on early feeding behavior and growth of Norwegian Red calves
}

\author{
Laura Whalin, ${ }^{1} \oplus$ Heather W. Neave, ${ }^{2,3} \odot$ Julie Føske Johnsen, ${ }^{4} \odot$ Cecilie M. Mejdell, ${ }^{4}{ }^{\oplus}$ \\ and Kristian Ellingsen-Dalskau ${ }^{4 *}(\mathbb{0})$ \\ ${ }^{1}$ Animal Welfare Program, Faculty of Land and Food Systems, University of British Columbia, 2357 Main Mall, Vancouver, BC, Canada V6T 1Z4 \\ ${ }^{2}$ Animal Behaviour and Welfare Team, AgResearch Ltd., Ruakura Research Centre, 3214 Hamilton, New Zealand \\ ${ }^{3}$ Department of Animal Science, Aarhus University, Foulum, 8830 Tjele, Denmark \\ ${ }^{4}$ Norwegian Veterinary Institute, PO Box 64, 1431 Ås, Norway
}

\section{ABSTRACT}

Some research has described a relationship between personality and feeding behavior at weaning in Holstein dairy calves; our objective was to determine if personality traits, especially sociability, are associated with differences in feeding behavior and growth in Norwegian Red calves. Our secondary objective was to assess the interaction between personality traits and gradual weaning method (by age or by concentrate intake) on the behavior and growth of calves. Twenty-seven Norwegian Red calves were housed in 7 groups of 3 to 5 calves, with group composition based on birthdate to ensure that there were no more than $21 \mathrm{~d}$ between the youngest and oldest calves. Calves had access to an automated milk and concentrate feeder with ad libitum access to concentrates, water, hay, and silage. Calves were semi-randomly assigned to be either gradually weaned by age at d 56, or weaned by intake, where weaning was initiated based on reaching specific concentrate intake targets. We measured milk intake, concentrate intake, and the number of unrewarded visits to the automated feeder during each of 5 experimental periods: preweaning (12 L/d; 10-30 d of age), weaning (milk allowance gradually reduced by method until completely weaned), weaning week ( $3 \mathrm{~d}$ before weaning and the first $7 \mathrm{~d}$ of $0 \mathrm{~L} / \mathrm{d}$ milk allowance), postweaning (20 d after complete milk removal), and the total experimental period (10-20 d postweaning). At 21 and 80 $\mathrm{d}$ of age, individual behavioral responses toward novelty and isolation (indicative of personality) were recorded in 3 personality tests: novel environment, novel object, and a social motivation test (time taken to return the group). At $83 \mathrm{~d}$ of age, a group novel object test was conducted. Principal component analysis revealed 3

Received June 14, 2021.

Accepted October 2, 2021.

*Corresponding author: kristian.ellingsen@vetinst.no factors interpreted as personality traits (playful/exploratory, vocal/active, interactive in group test) that together explained $56 \%$ of the variance. Calves that were more playful/exploratory consumed more milk per day preweaning and more concentrate per day over the experimental period. Calves that were more vocal/active (interpreted as a type of sociability trait where vocalizations and pacing serve to communicate with conspecifics when isolated from herd) had lower preweaning milk intakes and lower concentrate intakes over the experimental period. Calves that were more interactive in the group test (interpreted as a type of sociability trait when with other herd mates) had lower preweaning and weaning concentrate intakes. There was no interaction between personality traits and weaning method on feeding behavior or performance outcomes; however, calves that were weaned by intake (successfully reached all concentrate targets) had higher average daily gains postweaning, likely due to consuming more concentrate per day over the entire experiment, than calves who failed to reach all targets, or were weaned by age. We concluded that the sociability traits of Norwegian Red calves were related to individual differences in milk and concentrate intake. Although the relationship between personality and feeding behavior and growth did not depend on weaning method, gradual weaning based on individual concentrate intakes provides an opportunity for calves to wean at a pace that fits the needs of each individual calf.

Key words: gradual weaning, animal welfare, temperament, dual purpose

\section{INTRODUCTION}

In natural systems, cow and calf pairs together set the feeding schedule for the calf. In cow-calf contact systems and artificial rearing systems where calves are provided ad libitum milk, young calves drink frequently (Hutchison et al., 1962; Borderas et al., 2009; Kour et 
al., 2021) and may consume large amounts of milk (e.g., $15 \mathrm{~L} / \mathrm{d}$; Borderas et al., 2009). Calves naturally wean at variable ages (Reinhardt et al., 1978; Reinhardt and Reinhardt, 1981; Veissier et al., 1990) in a series of steps, including a gradual decrease from a high milk allowance, a steady increase in solid food consumption, and suckling attempts increasingly rejected by the mother (Enríquez et al., 2011). In cow-calf contact systems, weaning from a high milk allowance is a gradual process that usually includes decisions made by both the cow and her calf, and thus is individualized for the pair.

Differences in feeding behavior and growth around weaning may be partly related to personality (Neave et al., 2018, 2019), defined as individual differences in behavior that are consistent across time and contexts (Koolhaas et al., 1999; Réale et al., 2007). Personality has been linked to production characteristics in adult animals; for example, dairy cows that spent more time vocalizing and facing the herd during a social isolation test were described as nervous and produced less milk (Hedlund and Løvlie, 2015). Personality has also been described in younger animals; for example, calves who were more fearful weaned earlier, and more exploratory and active calves had greater final weight after weaning (Neave et al., 2019). Novelty tests, such as the novel environment and novel object tests, have frequently been used to assess fear (Forkman et al., 2007) and exploration (Perals et al., 2017) to draw conclusions about personality and feeding behavior in calves (Neave et al., 2018, 2019). In more natural systems, calves graze and suckle in a herd setting (Dwyer, 1961; Reinhardt and Reinhardt, 1981; Vitale et al., 1986) and often graze with preferred social partners (Reinhardt et al., 1978), suggesting that feeding is also a social event. Additionally, calves that are socially housed have greater concentrate intake shortly before and after complete removal of milk, show higher ADG from pre- to postweaning (Costa et al., 2015), and are less fearful of new feeds when tested 2 wk after weaning (Costa et al., 2014) than individually housed calves. Thus, individual differences in social behaviors during preweaning and the weeks shortly after complete removal of milk may play a role in the feeding behaviors of young calves. Sociability, or the motivation for individuals to remain close to their group (Sibbald and Hooper, 2004; Sibbald et al., 2006), has not been investigated in relation to variability in feeding behavior for calves during their first $3 \mathrm{mo}$ of age. Sociability is a personality dimension that is consistent over time in young calves (Lecorps et al., 2018), and is considered 1 of the 5 personality traits in animals (Réale et al., 2007). One experiment found that lambs who vocalized more during an open field test consumed less novel feed, leading authors to suggest that sociability and willingness for young animals to try new feeds may be linked (Villalba et al., 2009). Sociability may also play a role in early calf feeding behavior and subsequent growth.

Data from automatic milk feeders may be useful to understand calf personality (Neave et al., 2018, 2019), feeding behavior, and responses to weaning (de Passillé and Rushen, 2016; Rosenberger et al., 2017; Benetton et al., 2019). Similar to more natural systems, automatic milk feeders facilitate the feeding of high cumulative volumes of milk via a teat (Medrano-Galarza et al., 2017) while also allowing calves to determine their own feeding schedule in more than 2 meals (e.g., Benetton et al., 2019; Neave et al., 2019). Recent work has used technology to better understand dairy calf feeding behavior and weaning success. Individual dairy calves vary in their weaning ages when weaned based on concentrate intake (Roth et al., 2009; de Passillé and Rushen, 2016; Benetton et al., 2019). Calves that successfully reached specified concentrate targets consumed less milk and more concentrate over the experiment, and had similar weights to calves that were weaned based on age (Benetton et al., 2019). The described feeding and personality studies have used dairy animals (i.e., predominantly Holstein with some Brown Swiss calves), but no work to date has explored how personality traits affect feeding behavior and performance in dual-purpose calves, such as Norwegian Red cattle. Norwegian Red cattle are bred specifically for meat and dairy production, as well as for behavior traits (Steine et al., 2008). This breed may have different feeding and growth patterns, which may be influenced by personality in different ways than dairy breeds. A constructive replication of this earlier body of work examining concentrate-dependent weaning may be informative for the management of Norwegian Red calves.

The objective of this study was to determine how personality traits, especially sociability, are associated with differences in feeding behavior and growth during different weaning methods (weaned based on age or based on concentrate intake). We predicted that calves with exploratory and social personality traits would have higher growth and consume less milk and more concentrates. Our secondary objective was to assess the effect of the interaction between personality traits and gradual weaning method (by age or by concentrate intake) on the behavior and growth of calves. We predicted that more exploratory and social calves would wean at an earlier age when weaned by concentrate intake. We also predicted that calves weaned by concentrate intake would consume less milk and more concentrates compared with calves weaned by age. 


\section{MATERIALS AND METHODS}

This study took place from January to July 2018 at the Norwegian University of Life Science (NMBU) Livestock Production Research Centre in Ås, Norway. The study received ethics approval (ID 14682) from the Norwegian Animal Research Authority (part of the Norwegian Food Safety Authority). The calves were kept and cared for according to the Norwegian animal welfare act and the directive on keeping of cattle.

\section{Housing and Animal Management}

Thirty Norwegian Red calves (15 females, 15 males) were enrolled in the study. Within 30 min after birth, calves were removed from their dam, weighed (mean $\pm \mathrm{SD}, 40.3 \pm 6.8 \mathrm{~kg}$ ), and fed ad libitum colostrum (minimum of $2 \mathrm{~L}$ ) by bottle. A blood sample was taken from the jugular vein 24 to $48 \mathrm{~h}$ after birth, and serum was analyzed using a refractometer (Master hand-held refractometer, ATAGO). Calves were enrolled if serum total protein $>5.0 \mathrm{~g} / \mathrm{dL}$.

For the first $10 \mathrm{~d}$, calves were housed in individual, straw-bedded pens, and offered $12 \mathrm{~L}$ of whole milk per day (divided into 4 meals at 0600, 1000, 1400, and 2000 h) from a teat bucket. During this time, calves also had ad libitum access to hay, silage, concentrates, and water. On $10 \pm 1 \mathrm{~d}$ of age, calves were weighed and moved to a group pen $\left(3.3 \times 3.5 \mathrm{~m}: 11.55 \mathrm{~m}^{2}\right)$. The pens had an elevated lying area with a rubber mattress covered with a layer of sawdust and an activity and feeding area that was a slatted concrete floor. Pens were cleaned daily. Each of the 7 groups were filled in chronological order according to birthdate so that there were no more than $21 \mathrm{~d}$ between the youngest and oldest calves in each group. Each group consisted of 5 calves, except the last 2 groups, which consisted of 3 calves/group to minimize age differences between calves within the group (age range per group: $11 \pm 7 \mathrm{~d}$ ). One of the groups consisting of 5 calves included a calf that was not enrolled in the trial but needed to be group housed following standard farm practice. Calves were disbudded after entering the group pen at approximately 30 d of age (3 calves were disbudded after 2 mo due to health concerns and 7 calves were polled). Calves were hot-iron disbudded after being sedated with xylazine (Rompun), given a nerve block (Nervus cornualis) using local anesthesia, and provided a nonsteroidal antiinflammatory drug (Metacam, Boehringer Ingelheim Vetmedica $\mathrm{GmbH}$ ) for pain relief the following $2 \mathrm{~d}$.

Calves in group pens had access to milk from the automatic feeding system (CF500S, DeLaval Inc.) equipped with 1 artificial teat per group and barriers so that only 1 calf per group could feed at a time. Each automatic feeding system was equipped with 2 teats ( 1 teat per pen). The younger group of calves were given priority if 2 calves were at the artificial teats at the same time. Milk allowance delivered at each visit accrued hourly at a rate of $5 \%$ of the daily value every hour from midnight to $2000 \mathrm{~h}$, with a minimum and maximum meal size of 0.5 and $9 \mathrm{~L}$, respectively; thus, calves would need to visit the milk feeder at least twice to receive their total allotment of $12 \mathrm{~L} / \mathrm{d}$ during preweaning. Pelleted concentrate (Drøv Intro, Norgesfor AS) was offered ad libitum from the same computerized system used for milk. Only 1 calf per group could feed from the concentrate feeder at a time. Throughout the study, all calves had ad libitum access to water, hay, and silage, but these intakes were not measured. Daily intake of milk and concentrates, milk drinking speed, and unrewarded visits (not permitted to drink milk) were calculated by the same automatic feeding system. Calibration of all automated feeders was performed twice per week for each pen to ensure accurate dispensing of milk and concentrate portions.

\section{Milk Feeding and Weaning Methods}

Calves were randomly allocated to their weaning method by birth order as follows: weaned by age (at $\mathrm{d} 56 ; \mathrm{n}=14 ; 6$ males, 8 females) or weaned by intake of concentrates $(\mathrm{n}=16$ calves; 9 males and 7 females) using the random number function in Excel [ $\mathrm{fx}$ $=$ RANDOMBETWEEN $(1 ; 2)$; Microsoft Office Professional Plus 2016]. From 10 to $30 \mathrm{~d}$ of age, each calf was offered $12 \mathrm{~L}$ of whole milk per day. On d 30 of age, all calves received their first step-down in milk allowance; milk was reduced by $25 \%$ of the calf's average milk intake over the previous 3 d. From this point, weaning was different for calves based on their assigned weaning method. Calves weaned by age experienced a gradual reduction in milk (by $0.5 \pm 0.1 \mathrm{~L} / \mathrm{d}$ ) from d 42 to 56 , so that they were fully weaned by $\mathrm{d} 56$. Calves weaned by intake received subsequent reductions in milk allowance ( $25 \%$ of the average milk intake for the previous $3 \mathrm{~d}$ ) when they reached each of 3 concentrate intake targets (225, 675, and 1,300 g/d). Targets and age to begin eating concentrate were calculated as the average of the previous $3 \mathrm{~d}$, with the requirement that each of the 3 d met at least $50 \%$ of the target. When calves weaned by intake consumed an average of $225 \mathrm{~g}$ of concentrate for 3 consecutive days (successful intake; $\mathrm{n}=8$ ), they experienced their second milk reduction (25\% of the average milk intake for the previous $3 \mathrm{~d}$ ). Calves that failed to consume $225 \mathrm{~g}$ by $42 \mathrm{~d}$ of age were considered as a separate weaning group (failed intake; $\mathrm{n}=6$ ) and 
received their second reduction in milk allowance at 42 $\mathrm{d}$ of age. Once both successful-intake and failed-intake calves consumed an average of $675 \mathrm{~g}$ of concentrate for 3 consecutive days, milk was again reduced by $25 \%$ of the previous 3-d average (third reduction in milk). All calves in successful-intake and failed-intake groups completed weaning when $1,300 \mathrm{~g}$ of concentrate was consumed for 3 consecutive days (final reduction in milk to $0 \mathrm{~L} / \mathrm{d})$. These 3 concentrate targets $(225,675$, and $1,300 \mathrm{~g} / \mathrm{d}$ ) were recommended by the Bovine Alliance on Management and Nutrition (2017) and were the same targets used by Benetton et al. (2019).

\section{Data Recording and Calculations}

Feeding data (daily concentrate and milk intakes, milk drinking speed, and unrewarded visits to the milk feeder) were recorded by the automatic feeding system until $20 \mathrm{~d}$ after the calf completed weaning. To describe early concentrate feeding behavior, we determined the age (d) when the calf first ate at least 40 $\mathrm{g}$ of concentrate from the feeder (indicating the calf ate at least the previous $20 \mathrm{~g}$, which is the smallest portion dispensed by the feeder). We also recorded the age each calf first reached the concentrate consumption targets $(225,675$, and $1,300 \mathrm{~g} / \mathrm{d})$. We examined feeding behavior in 5 periods as follows: preweaning (full milk allowance; $10-30 \mathrm{~d}$ of age), weaning (milk allowance gradually reduced by method until completely weaned), weaning week (from $3 \mathrm{~d}$ before weaning to the first 7 $\mathrm{d}$ of $0 \mathrm{~L} / \mathrm{d}$ milk allowance), postweaning (20 d after complete milk removal), and the total experimental period (10-20 d postweaning). By design of the weaning methods, successful-intake and failed-intake calves were of variable ages during the weaning and postweaning periods, and all weaned-by-age calves were the same age during the weaning and postweaning periods.

\section{Health}

Weekly health checks were performed by a veterinarian using the Calf Health Scorer App (University of Wisconsin-Madison) as described by Renaud et al. (2018) and Wilson et al. (2020). The app facilitated the examination of each calf's respiratory system (nose, eye, ear, cough; McGuirk and Peek, 2014), fecal consistency (McGuirk, 2008), navel inflammation (adapted from Fecteau et al., 1997), joint swelling, and rectal temperature on 4-point scales with images and descriptions. Lung auscultations $(0=$ no lung consolidation detected; $1=$ some lung consolidation; $2=$ lung consolidation) were also recorded. We also performed daily visual examinations of all calves, and any calf appearing ill received a full examination as described above. Following Benetton et al. (2019), calves were considered to experience sickness (binary variable) if, during any single weekly health check, they scored a 5 or higher for their respiratory system (nose, eye, ear, cough, and temperature), had a diarrhea score $>2$, had an appetite score of 3 , lung auscultation had consolidation, or overall score in the app was $>6$. If calves were experiencing diarrhea, they were given oral electrolytes (Hydrafeed, NYdiet Grassland Agro) twice per day following farm protocols. Health checks were conducted to control for the effect of illness on outcome measures (i.e., health was an explanatory variable, not outcome variable). Calves were also weighed twice per week to calculate ADG for each period (whole-body weigh scale, BioControl).

\section{Personality Tests}

Novelty Tests. The novel environment and novel object tests were chosen to characterize calves' responses to new situations to target personality traits of exploration or fearfulness, following previous studies in dairy calves (Lecorps et al., 2018; Neave et al., 2018, 2019). The novel environment test exposed calves to an arena that was empty and unfamiliar, and calves could voluntarily interact with a bucket they had never seen in the novel object test. These tests took place in a test arena $(4.90 \mathrm{~m} \times 3.39 \mathrm{~m})$ with a concrete floor lightly covered with sawdust. Calves did not have visual contact outside the test arena.

Calves were tested individually in 1 test per day over 2 consecutive days (test $d$ 1: novel environment, test $d$ 2: novel object test). Due to differences in age between groupmates (age range per group: $11 \pm 7 \mathrm{~d}$ ), calves were first tested when they were $21 \pm 3 \mathrm{~d}$ of age (1 wk before initial milk reduction for each individual). Calves were then retested in each test at $80 \pm 9 \mathrm{~d}$ age ( $1 \mathrm{wk}$ after the last calf in the group completed weaning; all calves in the group retested on the same days). Calf testing order was randomized. At the time of testing, the calf was gently guided into the test pen. Calves were video recorded continuously for $10 \mathrm{~min}$ using 1 camera (GoPro Hero5, GoPro Inc.) $3.62 \mathrm{~m}$ above the testing arena. After $10 \mathrm{~min}$ in the novel environment test, calves remained for 20 min to habituate to the testing arena and a 17.2-m long alley half covered in green tarp to prevent visual contact outside of the test arena. The alley would later be used for the social motivation test. In the novel object test, a black 10-L bucket was centered in the testing arena. If calves never touched the object, they were assigned the maximum latency of $10 \mathrm{~min}(601 \mathrm{~s})$. All videos were scored using 
Table 1. Ethogram (adapted from Neave et al., 2018) of behaviors scored during each of the 2 novelty tests (novel environment and novel object) when calves $(\mathrm{n}=28)$ were tested individually at (mean $\pm \mathrm{SD}) 21 \pm 3 \mathrm{~d}$ and $80 \pm 9 \mathrm{~d}$ age

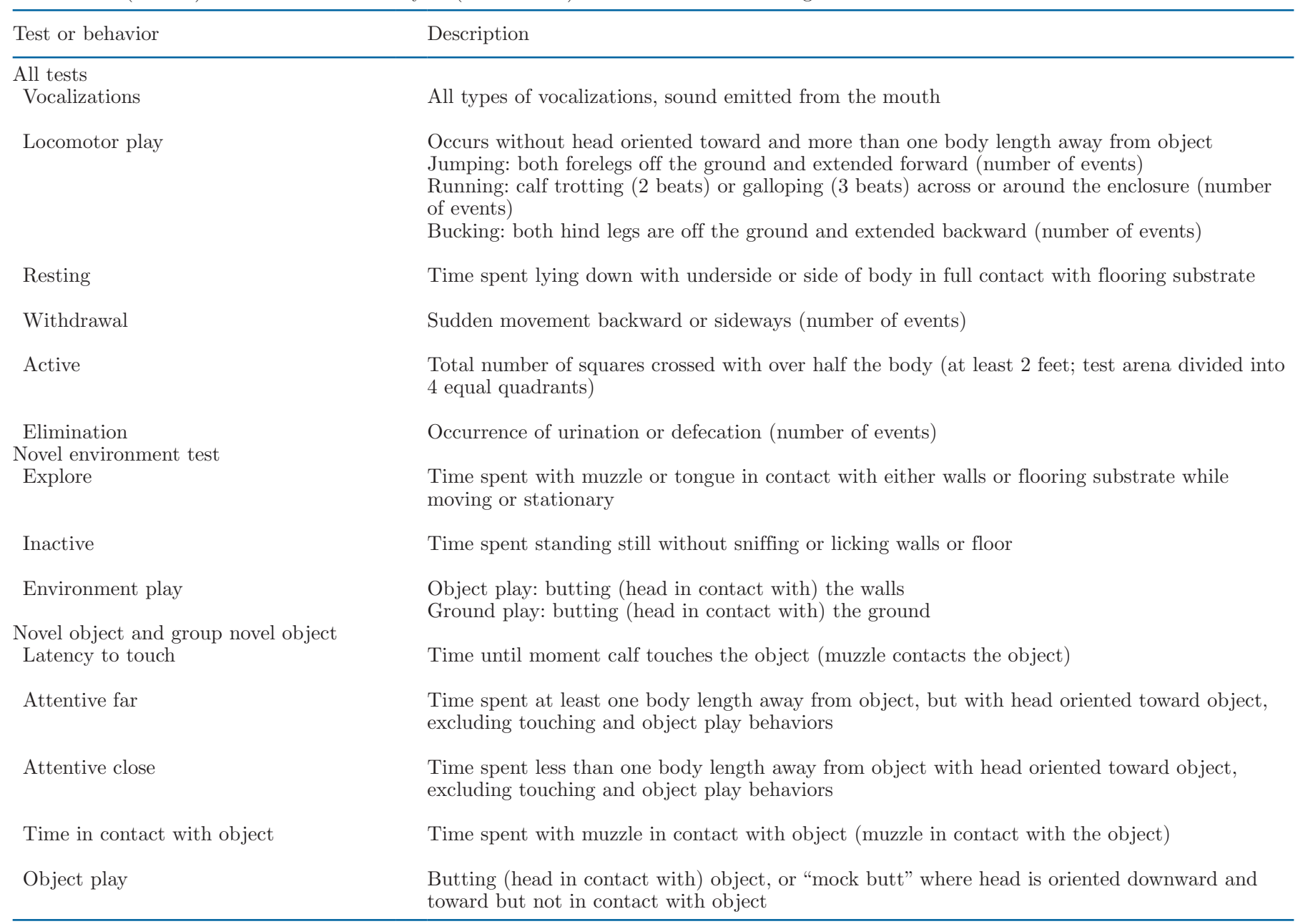

${ }^{1}$ In the group novel object test, all calves $(n=27)$ in the group $(n=7)$ were exposed to the same novel object at the same time at $83 \pm 9 \mathrm{~d}$ of age.

BORIS (v. 6.0.6; Friard and Gamba, 2016). A single observer scored all behaviors in all tests using an ethogram (Table 1; adapted from Neave et al., 2018) after establishing high intraobserver reliability for each test $(\geq 0.8)$. Vocalizations were scored from the camera recording.

Social Motivation Test. Sociability as a personality trait has previously been explored in dairy calves and cows (Gibbons et al., 2010; Lecorps et al., 2018). The social motivation test was selected to better understand how individual sociability may play a role in feeding behavior. Each calf in the group completed the social motivation test on the same day so that all calves had previously been tested in the novel environment and novel object tests. This meant that some calves may have experienced a longer gap between testing in the novelty tests and the first social motivation test (test d 3, age: $26 \pm 8 \mathrm{~d}$ ). All calves retested after weaning experienced the 3 tests (i.e., novel environment, novel object, then social motivation test) on consecutive days beginning on $80 \pm 9 \mathrm{~d}$ of age ( $1 \mathrm{wk}$ after the last calf in the group had been weaned). The test took place in the same testing arena that the calves were exposed to in the novelty tests. Following the social motivation test procedures described by Lecorps et al. (2018), calves were given 10 min to habituate as a group to the arena (same arena where novelty tests took place) on the day of testing. Calves were then randomly moved one at a time to the holding area at the end of the $17.2 \mathrm{~m}$ long alley. Each calf was held in the holding area for $5 \mathrm{~min}$, and vocalizations were recorded. Calves could still see their groupmates when in the holding pen. At the end of the $5 \mathrm{~min}$, the door was opened so that the calf could return to the group. The time taken to return within 5 $\mathrm{m}$ of the group was recorded.

Group Novel Object Test. Each of the above tests involved moving the calf into a solitary environment that was unlike the typical experience of a group- 
housed calf. Calves are herd animals that perform social behaviors and feed together (Reinhardt et al., 1978; Reinhardt and Reinhardt, 1981; Veissier et al., 1990) and are usually managed as a group after preweaning (USDA, 2016). A caution of personality testing is that the tests should be species appropriate (Carter et al., 2013); fear tests (in isolation) in farm animals have received critique for not considering the gregariousness of animals (Forkman et al., 2007). However, few studies have explored personality in group or herd tests (e.g., Foris et al., 2018). Given that calves are herd animals, and were managed in group housing in our study, investigating the responses of individuals toward novelty when in a social setting may help to better characterize the personalities of the animals (Krause et al., 2010). A group novel object test was performed once on the last day of testing so as to not interfere with previous tests (age: $83 \pm 9 \mathrm{~d}$ ). In the group novel object test, a green and yellow 10-L bucket was centered in the same testing arena that had been used for all previous tests. The group of calves was held for $10 \mathrm{~min}$ in an adjacent arena $(2.7 \times 4.6 \mathrm{~m})$ with an electronic garage door separating the 2 arenas. After $10 \mathrm{~min}$, the garage door was opened and all calves had equal access to the novel object. Video was recorded for $10 \mathrm{~min}$. If calves never touched the object, they were assigned the maximum latency of $10 \mathrm{~min}(601 \mathrm{~s})$. The same observer scored the behaviors described in the ethogram (Table 1).

\section{Statistical Analysis}

Following Benetton et al. (2019), who calculated sample sizes based on ADG and used the same weaning methods as our study, we enrolled 30 calves. Data were cleaned and visualized using R Studio (version 1.4.1106 "Tiger Daylily"; https://www.r-project.org/) with tidyverse (Wickham et al., 2019), ggpubr (Kassambara, 2020), and writexl (Ooms, 2020). On 5 experimental days, there were feed delivery issues with the automatic feeders, and these were removed from the data set. On 9 experimental days, a single calf was removed due to poor health or an error in the feeding allotment. Average milk intake, concentrate intake, milk drinking speed, and unrewarded visits to the milk feeder for each experimental period for each calf were calculated. Average daily gain was calculated from weights recorded twice per week.

All analyses were performed using SAS (SAS University Edition; SAS Institute Inc.) with calf as the experimental unit. Two calves (weaned by intake, 1 male and 1 female) were removed from the study due to persistent diarrhea leading to abnormal growth and feed intake, and 1 calf (weaned by age, male) was pre- maturely removed from the group pen and unable to complete all of the tests, resulting in 27 calves included for analysis (weaned by intake: $\mathrm{n}=14,8$ males and 6 females; weaned by age: $\mathrm{n}=13,5$ males, 8 females). The weaned-by-intake calves were further divided into "successful-intake" ( $\mathrm{n}=8,3$ males and 5 females; calves consumed $225 \mathrm{~g}$ of concentrate by $42 \mathrm{~d}$ of age and then reached all subsequent concentrate intake targets) and "failed-intake" ( $\mathrm{n}=6,5$ males and 1 female; calves did not consume $225 \mathrm{~g}$ by $42 \mathrm{~d}$ of age and were forced to step-down in milk intake at $42 \mathrm{~d}$ of age; these calves reached the subsequent targets of $675 \mathrm{~g}$ and 1,300 $\mathrm{g}$ ).

All feeding and behavior measures were scrutinized using PROC UNIVARIATE and normalized as required using $\log _{10}$ transformation $[\log (\mathrm{y}+1)$; time to return to group; vocalizations during the novel object, environment, and group test; withdrawals in novel object and environment; latency to touch object in both group and individual novel object tests; time spent touching object; time spent looking at the object and near in both group and individual novel object tests; and locomotor play in the novel environment] and square root (group test object play and time spent touching object in group test). Pearson correlation coefficients for behaviors recorded during each personality test (at 21 and $80 \mathrm{~d}$ of age) were calculated with PROC CORR. Behaviors were correlated except attentive far $(P=$ $0.55)$ during the novel object test, and this variable was excluded]; therefore, each behavior was averaged across test repeats (age 21 and $80 \mathrm{~d}$ ) for each test (except the group novel object test, which only had one repeat).

Thirty-one variables were recorded in the novelty, social motivation, and group object tests. Following Neave et al. (2018), variables that rarely occurred were excluded from analysis (8 variables excluded: over 50\% of calves did not engage in resting or elimination behaviors during the novel object, novel environment, and group novel object tests; over $90 \%$ of calves did not engage in environmental play during the novel environment test; over $50 \%$ of calves engaged in $<2$ withdrawals during the group novel object test), resulting in 23 variables subjected to a principal component analysis (PCA) using SAS with varimax rotation to condense correlated measures into principal components (Van Reenen et al., 2004; Neave et al., 2018). Some variables had low communality estimates $\left(\mathrm{h}^{2}<0.30\right)$ and were thus removed from the PCA analysis (withdrawals in the novel object, time spent looking at the object while near in both group and individual novel object tests, locomotor play in the group test, and vocalizations during the group test). The resulting PCA achieved sampling adequacy $(=0.50)$ with 18 variables as follows: vocalizations (from each test), time to return to 
the group (social motivation test); locomotor play and activity (novel object and environment tests); latency to touch, time spent touching object, and object play (both group and individual novel object tests); exploration, inactivity, and withdrawals (novel environment test), and time spent looking at the object and far away (group novel object test) were included for analysis. Three principal components with eigenvalues $>1$ accounted for $56 \%$ of the variance; these were retained for further analysis (hereafter referred to as factor 1 , factor 2 , and factor 3 ). Individual calf scores on each of the factors were extracted using the regression method.

We first tested whether weaning method and sickness affected how calves scored on the personality trait factors. This model tested the fixed effects of weaning method (weaned by age, successful intake, or failed intake), sickness (binary variable: sick or not sick), birth weight, sex, and group order on each of the 3 factor scores (factor 1, factor 2, or factor 3), with group as a random effect. None of the fixed effects had a significant effect on factor scores. We then tested whether weaning method and personality (factors 1, 2, or 3) affected measures of feeding behavior and performance during each of the 5 experimental periods, with group included as a random effect. Each model tested the fixed effects of weaning method and factor score, with birth weight, sickness, and weaning age as covariates, on the following response variables: ADG, milk intake, concentrate intake, first day to eat concentrate, milk drinking speed, and unrewarded visits to the milk feeder. Sex and order of entry into the group (group order) were also included as covariates in initial models, but were removed using backward elimination if $P>0.30$. Group order was retained in the models for milk intake (preweaning), concentrate intake (total experiment), ADG (preweaning), and unrewarded visits (preweaning). Sex was retained in the model for milk intake (weaning and weaning week), ADG (weaning week, postweaning, total experiment), milk drinking speed (preweaning), and unrewarded visits (total experiment). Both group order and sex were retained in the models for concentrate intake (pre- and postweaning), milk drinking speed (weaning week), unrewarded visits (weaning), and the first day to consume concentrate. We included interactions between weaning method and factor score, but there were no significant interactions, and thus the interaction terms were removed. Significance was declared at $P \leq 0.05$ and a tendency at $P \leq 0.10$.

The observer who did the primary data analysis approached this study with on-farm experience and a deep appreciation for caring for and learning from each individual animal. The analysis and interpretation are inherently influenced by these values and interest in the natural living component of animal welfare (Fraser et al., 1997). All authors, except HWN (who was involved with data analysis) were aware of group allocation throughout the experiment. Data from the study is stored on the server of the Norwegian Veterinary Institute and is available upon request.

\section{RESULTS}

\section{Calf Health}

Most calves in our study experienced a period of illness, particularly diarrhea. Twenty-six of the calves $(96 \%)$ were treated with oral electrolytes for diarrhea, and 2 calves were removed from the trial due to persistent clinical diarrhea. Using the sickness criteria described in the materials and methods (following Benetton et al., 2019), 17 of the calves who remained in the trial were considered sick during at least 1 health check, and this was included as an explanatory variable in all the models. Six of the calves were considered sick during more than 1 health check. No calves were sick at the time of personality testing.

\section{Personality Traits and Relationship to Feeding Behavior and Growth}

The behavioral responses of calves in each of the personality tests are presented in Table 2 , and the loadings for each factor from the PCA (interpreted as personality traits) are reported in Table 3. Interpretations of the loadings for each factor should be considered a subjective label for the suite of behavioral responses observed in response to the putatively stressful novel situations; individuals scoring "high" on a factor are considered to express more of this trait while individuals scoring "low" on a factor would express less of this trait, but not necessarily less stress in response to the situation as stress can be behaviorally expressed in different ways. Factor 1 explained $25.2 \%$ of the total variance and contained high positive loadings for exploring, locomotor play, time in contact with the object, and object play. There was also a high negative loading for inactivity. Calves that scored high on factor 1 were termed "playful/exploratory." Factor 2 explained 17.1\% of the total variance and had high positive loadings for activity and vocalizations in the novelty tests. Calves that scored highly on factor 2 were termed "vocal/active," which we suggested reflected a type of sociability trait in which calves were responding to social isolation by attempting to communicate with their herd mates with increased vocalizations and activity. The loading for vocalizations in the social motivation test (0.57) 
approached the cut-point of 0.60 for a high loading and thus supports our interpretation that this factor is related to sociability. This interpretation is also supported in previous research suggesting vocalizations are a response to social separation when tested in novel situations (Van Reenen et al., 2004, 2005). Factor 3 explained $14.2 \%$ of the total variance with high positive loadings for time in contact with the object and object play during the group novel object test and withdrawals in the novel environment. There was also a high negative loading for time looking at the object when standing far away in the group novel object test. Calves that scored high on factor 3 were termed "interactive in group test," which we suggested reflected a type of sociability trait related to responding to novelty when in a group setting with other herd mates. Behaviors recorded in the group novel object did not load on the same factor as the behaviors recorded in the individual novel object test, indicating behaviors in these 2 tests were not related.

There were no interactions between the factor scores and weaning methods, indicating that calves with different personality traits did not perform differently based on the weaning method. Thus, only the main effect of each factor (personality trait) on feeding behavior and growth are presented. Personality traits were not associated with growth measures, but did have some associations with feed intake during the experimental periods (Table 4). Calves that scored higher on factor 1 (playful/exploratory trait) had higher preweaning milk intakes per day and higher concentrate intakes per day during the weaning week, postweaning, and over the total experimental period. In contrast, calves scoring higher on factor 2 (sociability vocal/active trait)

Table 2. Behavioral responses (raw arithmetic mean \pm SD) of calves $(n=27)$ when tested individually at $21 \pm 3 \mathrm{~d}$ and $80 \pm 9 \mathrm{~d}$ of age in a novel environment test $(10 \mathrm{~min})$, novel object test $(10 \mathrm{~min})$, and social motivation test $(5 \mathrm{~min})^{1}$

\begin{tabular}{|c|c|c|c|}
\hline Test or behavior & Mean & $\mathrm{SD}$ & Range \\
\hline \multicolumn{4}{|l|}{ Novel environment test } \\
\hline Vocalizations (no.) & 5.2 & 4.9 & $0-19.5$ \\
\hline Elimination (no.) & 0.48 & 0.55 & $0-2$ \\
\hline Active (no. of quadrants crossed) & 33.9 & 11.7 & $10.5-63.5$ \\
\hline Inactive $(\mathrm{s})$ & 203.5 & 84.4 & $50.8-442.0$ \\
\hline Exploring walls or floor (s) & 224.8 & 66.4 & $57.4-366.7$ \\
\hline Locomotor play (no.) & 11.1 & 9.8 & $0.5-38$ \\
\hline Environment play-object play (s) & 10.6 & 26.2 & $0-126.4$ \\
\hline Environment play-ground play (s) & 1.4 & 4.9 & $0-24.8$ \\
\hline Withdrawal (no.) & 1.2 & 1.3 & $0-5.5$ \\
\hline \multicolumn{4}{|l|}{ Novel object test } \\
\hline Vocalizations (no.) & 5.8 & 5.4 & $0-18.5$ \\
\hline Elimination (no.) & 0.54 & 0.54 & $0-2$ \\
\hline Latency to touch $(\mathrm{s})^{1}$ & 104.5 & 142.7 & $3.6-601$ \\
\hline Time in contact with object $(\mathrm{s})$ & 23.0 & 18.6 & $0-84.3$ \\
\hline Attentive close (s) & 21.5 & 10.3 & $6.3-48.5$ \\
\hline Attentive far (s) & 24.8 & 10.9 & $2.8-55.8$ \\
\hline Object play $(\mathrm{s})$ & 4.8 & 10.7 & $0-44.7$ \\
\hline Locomotor play (no.) & 7.5 & 5.3 & $0.5-19.5$ \\
\hline Withdrawal (no.) & 0.48 & 0.66 & $0-2.5$ \\
\hline Active (no. of quadrants crossed) & 33.3 & 11.4 & $4.5-63.5$ \\
\hline \multicolumn{4}{|l|}{ Group novel object test } \\
\hline Vocalizations (no.) & 2.1 & 2.5 & $0-8$ \\
\hline Elimination (no.) & 0.037 & 0.19 & $0-1$ \\
\hline Latency to touch ${ }^{2}(\mathrm{~s})$ & 198.5 & 219.6 & $22.5-601$ \\
\hline Time in contact with object (s) & 48.6 & 50.7 & $0-215.6$ \\
\hline Attentive close (s) & 27.4 & 16.9 & $4.0-68.8$ \\
\hline Attentive far $(\mathrm{s})$ & 33.2 & 20.7 & $6.7-98.7$ \\
\hline Object play $(\mathrm{s})$ & 1.9 & 4.5 & $0-20.0$ \\
\hline Locomotor play (no.) & 23.3 & 13.9 & $0-49$ \\
\hline Withdrawal (no.) & 1.6 & 1.6 & $0-6$ \\
\hline Active (no. of quadrants crossed) & 32.7 & 19.7 & $4-99$ \\
\hline \multicolumn{4}{|l|}{ Social motivation test } \\
\hline Vocalizations (no.) & 5.4 & 4.3 & $0-18.5$ \\
\hline Time to return to group (s) & 35.2 & 35.3 & $4.1-142.1$ \\
\hline
\end{tabular}

${ }^{1}$ The group novel object test $(10 \mathrm{~min})$ occurred once at $83 \pm 9 \mathrm{~d}$ of age for calves $(\mathrm{n}=27)$ in their groups $(\mathrm{n}$ $=7$ ). Behaviors were averaged across repeated tests for each calf.

${ }^{2}$ Calves that did not touch the object were assigned the maximum latency of 10 min $(601 \mathrm{~s})$. 
Table 3. Coefficients (loadings) of the eigenvectors for the first 3 factors extracted by principal component analysis of behavioral measures recorded when calves $(n=27)$ were tested in novel environment, novel object, social motivation, and group novel object tests ${ }^{1}$

\begin{tabular}{|c|c|c|c|}
\hline Variable & Factor 1 & Factor 2 & Factor 3 \\
\hline \multicolumn{4}{|l|}{ Novel environment test } \\
\hline Exploring (s) & $0.68205^{*}$ & 0.11994 & 0.00816 \\
\hline Vocalizations (no.) & -0.34244 & $0.766^{*}$ & 0.18918 \\
\hline Locomotor play & $0.61093^{*}$ & 0.34565 & 0.06032 \\
\hline Withdrawals (no.) & 0.15158 & -0.23757 & $0.68551^{*}$ \\
\hline Active (no. of quadrants crossed) & 0.33732 & 0.59048 & -0.25969 \\
\hline Vocalizations (no.) & -0.04395 & $0.87451^{*}$ & 0.00646 \\
\hline Latency to touch object $(\mathrm{s})$ & -0.36146 & -0.38094 & -0.14708 \\
\hline Time in contact with object $(\mathrm{s})$ & $0.81301^{*}$ & 0.10569 & 0.07993 \\
\hline Object play $(\mathrm{s})$ & $0.75658^{*}$ & -0.30696 & 0.21543 \\
\hline \multicolumn{4}{|l|}{ Group novel object test } \\
\hline Attentive far (s) & 0.25188 & -0.13381 & $-0.70839^{*}$ \\
\hline \multicolumn{4}{|l|}{ Social motivation test } \\
\hline Time taken to return to group (s) & -0.11513 & -0.40652 & -0.52613 \\
\hline Eigenvalues & 4.5 & 3.1 & 2.6 \\
\hline Variance explained & 25.2 & 17.1 & 14.2 \\
\hline Interpretation (suggested label) & Playful/exploratory & Sociability: vocal/active & Sociability: interactive in group test \\
\hline
\end{tabular}

${ }^{1}$ Behaviors were averaged across each repeated test, except for group novel object tests (as calves were only given this test once). Eigenvalues and proportion of total variation explained by each factor are reported, and suggested labels for each factor are offered.

*High loadings $(\geq 0.60)$ are indicated with an asterisk.

Table 4. Relationships between factor scores and performance and feed intake measures for calves $(\mathrm{n}=27)$ during each of 5 experimental periods: preweaning (full milk allowance; 10-30 d of age), weaning (milk allowance gradually reduced by method until completely weaned), weaning week ( $3 \mathrm{~d}$ before weaning and the first $7 \mathrm{~d}$ of $0 \mathrm{~L} / \mathrm{d}$ milk allowance), postweaning ( $20 \mathrm{~d}$ postweaning), and the total experimental period (10-20 d postweaning)

\begin{tabular}{|c|c|c|c|c|c|c|c|c|c|}
\hline \multirow[b]{2}{*}{ Measure } & \multicolumn{3}{|c|}{$\begin{array}{c}\text { Factor } 1 \\
\text { (playful/exploratory) }\end{array}$} & \multicolumn{3}{|c|}{$\begin{array}{c}\text { Factor } 2 \\
\text { (vocal/active) }\end{array}$} & \multicolumn{3}{|c|}{$\begin{array}{c}\text { Factor } 3 \\
\text { (interactive in group test) }\end{array}$} \\
\hline & $\begin{array}{c}\text { Effect } \\
\text { direction }^{1}\end{array}$ & $F$-value & $P$-value & $\begin{array}{l}\text { Effect } \\
\text { direction }\end{array}$ & $F$-value & $P$-value & $\begin{array}{c}\text { Effect } \\
\text { direction }\end{array}$ & $F$-value & $P$-value \\
\hline \multicolumn{10}{|l|}{$\overline{\mathrm{ADG}(\mathrm{kg} / \mathrm{d})}$} \\
\hline Preweaning & & 1.18 & 0.31 & & 0.03 & 0.86 & & 0.18 & 0.68 \\
\hline Weaning & & 0.14 & 0.71 & & 0.11 & 0.75 & & 0.02 & 0.90 \\
\hline Total experiment & & 0.22 & 0.65 & & 0.00 & 0.99 & & 0.66 & 0.44 \\
\hline \multicolumn{10}{|l|}{ Milk intake (L/d) } \\
\hline Preweaning & + & 9.72 & $0.012^{*}$ & - & $7.12^{*}$ & $0.026^{*}$ & & 0.55 & 0.48 \\
\hline Weaning & & 0.32 & 0.58 & & 0.41 & 0.53 & & 0.43 & 0.53 \\
\hline Total experiment & & 0.39 & 0.55 & & 0.05 & 0.82 & & 0.33 & 0.58 \\
\hline \multicolumn{10}{|c|}{ Concentrate intake $(\mathrm{kg} / \mathrm{d})$} \\
\hline Preweaning & & 1.46 & 0.26 & & 0.42 & 0.54 & - & $5.28^{*}$ & $0.05^{*}$ \\
\hline
\end{tabular}

${ }^{1}$ Effect direction is provided when the main effect is $P \leq 0.1$.

$* P \leq 0.1$. 


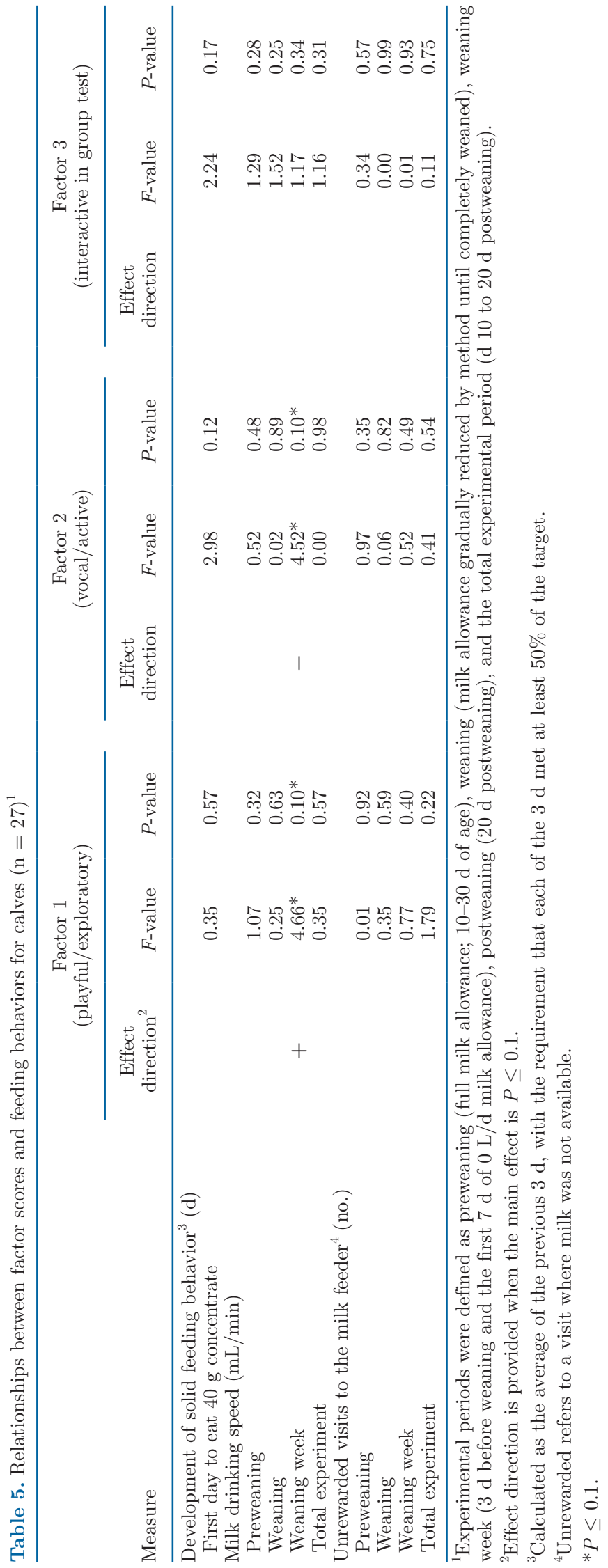

had lower preweaning milk intake per day, and lower concentrate intake per day over the total experimental period. Calves scoring higher on factor 3 (sociability interactive in group test) had lower preweaning and weaning concentrate intake per day.

Few relationships were detected between the 3 personality traits and calf behavior at the milk feeder (Table 5). Calves scoring higher on factor 1 (playful/ exploratory trait) tended to have a higher milk drinking speed, whereas calves scoring higher on factor 2 (sociability vocal/active trait) tended to have a lower milk drinking speed during the weaning week.

\section{Effects of Weaning Methods on Feeding Behavior and Growth}

We found no evidence of interactions between factor scores and weaning method. However, weaning method did affect calf feeding behavior and performance. Across weaning methods, there was large variation in the age when calves reached each of the concentrate intake targets (Table 6); for example, calves ranged from 33 to $61 \mathrm{~d}$ of age before they consumed $225 \mathrm{~g}$ of concentrate. Calves who failed to consume $225 \mathrm{~g}$ by 42 $\mathrm{d}$ of age (failed-intake method) took approximately 2 wk longer to start consuming concentrate (at least 40 g) than both the successful-intake calves $\left(t_{2,8}=3.93\right.$, $P<0.005)$ and the calves weaned by age $\left(t_{2,8}=3.61\right.$, $P<0.01$; Table 7). Descriptively, failed-intake calves were approximately $2 \mathrm{wk}$ older than successful-intake and weaned-by-age calves when they consumed 1,300 g. Most calves who were weaned by age were not consuming $1,300 \mathrm{~g}$ of concentrates until after weaning (only 3 out of 14 calves consumed 1,300 g before weaning at 56 d of age).

Average daily gain of calves in each weaning method over the 5 experimental periods are presented in Figure 1. Successful-intake calves had a higher ADG during the weaning week and postweaning compared with failed-intake (weaning week: $t_{2,10}=3.45, P<0.01$; postweaning: $\left.t_{2,10}=2.12, P=0.06\right)$ and weaned-by-age calves (weaning week: $t_{2,10}=2.38, P=0.04$; postweaning: $\left.t_{2,10}=2.93, P<0.02\right)$. Failed-intake calves tended to have a lower ADG during weaning week than calves weaned by age $\left(t_{2,10}=1.99, P=0.07\right)$. Average daily gain did not differ between weaning methods during preweaning $\left(F_{2,9}=0.04 ; P=0.96\right)$, weaning $\left(F_{2,11}=\right.$ $0.74, P=0.50)$, or over the total experiment $\left(F_{2,10}=\right.$ $1.59, P=0.25)$.

Milk intake differed between weaning methods at preweaning, weaning, and over the experiment (Figure 1). Before weaning, when all calves were offered $12 \mathrm{~L} / \mathrm{d}$ of milk, failed-intake calves consumed less milk per day than calves weaned by age $\left(t_{2,9}=2.83, P=\right.$ 
Table 6. Age (mean $\pm \mathrm{SD})$ of all calves $(\mathrm{n}=28)$ when they reach concentrate intake targets from 10 of age to $20 \mathrm{~d}$ after complete removal of milk

\begin{tabular}{|c|c|c|c|c|c|c|c|c|c|}
\hline Measure & \multicolumn{6}{|c|}{ Weaned by intake ${ }^{1}$} & & & \\
\hline \multicolumn{10}{|l|}{ Development of solid feeding behavior ${ }^{3}$} \\
\hline First day to eat $225 \mathrm{~g}$ of concentrate (d) & 35.6 & 3.0 & $33-42$ & 53.3 & 5.2 & $45-61$ & 45.9 & 5.1 & $36-53$ \\
\hline First day to eat $675 \mathrm{~g}$ of concentrate (d) & 51.9 & 9.9 & $38-70$ & 61.7 & 7.1 & $54-74$ & 53.5 & 3.7 & $46-59$ \\
\hline
\end{tabular}

${ }^{1}$ All calves were offered $12 \mathrm{~L} / \mathrm{d}$ of milk until d 30; then, milk allowance was reduced to $75 \%$ of the calf's average milk intake over the previous $3 \mathrm{~d}(\mathrm{n}=28)$. Calves enrolled in the weaning by intake method received the new milk allowance achieved at $\mathrm{d} 30$ until $225 \mathrm{~g}$ of concentrate was consumed $3 \mathrm{~d}$ in a row (successful intake; $\mathrm{n}=8$ ), or they were $42 \mathrm{~d}$ of age (failed intake; $\mathrm{n}=6$ ). All calves except one met all subsequent targets. Once this goal was reached, milk allowance was decreased by $25 \%$ of the average milk intake for the previous $3 \mathrm{~d}$. Once the calf ate $675 \mathrm{~g}$ for 3 consecutive days, milk was once again reduced by $25 \%$ of the previous 3 -d average. Calves received this final milk allowance until $1,300 \mathrm{~g}$ of concentrate was consumed $3 \mathrm{~d}$ in a row, at which point all milk was removed.

${ }^{2}$ All calves were offered $12 \mathrm{~L} / \mathrm{d}$ of milk until d 30, and then milk allowance was reduced to $75 \%$ of the calf's average milk intake over the previous $3 \mathrm{~d}(\mathrm{n}=28)$. Calves weaned by age $(\mathrm{n}=14)$ experienced a gradual reduction in milk (by $0.5 \pm 0.1 \mathrm{~L} / \mathrm{d})$ from $\mathrm{d} 42$ to 56 , so that they were fully weaned by d 56 .

${ }^{3}$ Calculated as the average of the previous $3 \mathrm{~d}$, with the requirement that each of the $3 \mathrm{~d}$ met at least $50 \%$ of the target.

$0.02)$ but similar amounts of milk per day as successfulintake calves $\left(t_{2.9}=0.81, P=0.44\right)$. During weaning, successful-intake calves consumed less milk per day than weaned-by-age calves $\left(t_{2,10}=-3.00, P=0.01\right)$ and similar amounts to failed-intake calves $\left(t_{2,10}=0.59\right.$, $P=0.57)$. Over the total experiment, both successful-

Table 7. Least squares means $( \pm \mathrm{SE})$ of behavior at the milk feeder and behavioral response to weaning for calves $(\mathrm{n}=27)$ in each weaning method during each of 5 experimental periods: preweaning (full milk allowance; 10-30 d of age), weaning (milk allowance gradually reduced by method until completely weaned), weaning week ( $3 \mathrm{~d}$ before weaning and the first $7 \mathrm{~d}$ of $0 \mathrm{~L} / \mathrm{d}$ milk allowance), postweaning (20 d postweaning), and the total experimental period (10-20 d postweaning)

\begin{tabular}{|c|c|c|c|c|c|c|}
\hline Measure & \multicolumn{4}{|c|}{ Weaned by intake ${ }^{1}$} & & \\
\hline \multicolumn{7}{|l|}{ Development of solid feeding behavior $^{3}$} \\
\hline First day to eat $40 \mathrm{~g}$ of concentrate & $27.34^{\mathrm{a}}$ & 2.89 & $45.01^{\mathrm{b}}$ & 3.29 & $32.40^{\mathrm{a}}$ & 2.25 \\
\hline \multicolumn{7}{|l|}{ Milk drinking speed $(\mathrm{mL} / \mathrm{min})$} \\
\hline Weaning week & 293.22 & 43.52 & 327.66 & 56.07 & 255.45 & 36.98 \\
\hline Total experiment & 617.51 & 62.88 & 550.23 & 88.00 & 598.97 & 45.20 \\
\hline \multicolumn{7}{|c|}{ Unrewarded visits to the milk feeder ${ }^{4}$ (no./d) } \\
\hline Preweaning & $1.01^{\mathrm{a}, \mathrm{x}}$ & 0.60 & $0.11^{\mathrm{a}}$ & 0.75 & $2.56^{\mathrm{b}, \mathrm{y}}$ & 0.49 \\
\hline Weaning & $12.46^{\mathrm{x}}$ & 3.52 & $24.02^{y}$ & 5.00 & $8.02^{\mathrm{x}}$ & 3.05 \\
\hline Weaning week & 13.61 & 3.32 & 14.49 & 4.51 & 12.19 & 2.36 \\
\hline Total experiment & 8.34 & 1.99 & 10.22 & 2.67 & 7.09 & 1.41 \\
\hline
\end{tabular}

${ }^{\mathrm{a}, \mathrm{b}}$ Means with different superscripts within a row indicate a significant difference $(P \leq 0.05)$.

${ }^{\mathrm{x}, \mathrm{y}}$ Means with different superscripts within a row indicate a tendency to differ $(0.05<P \leq 0.1)$ between successful-intake, failed-intake, and weaned-by-age calves.

${ }^{1}$ All calves were offered $12 \mathrm{~L} / \mathrm{d}$ of milk until d 30, and then milk allowance was reduced to $75 \%$ of the calf's average milk intake over the previous $3 \mathrm{~d}(\mathrm{n}=28)$. Calves enrolled in the weaning by intake method received the new milk allowance achieved at $\mathrm{d} 30 \mathrm{until} 225 \mathrm{~g}$ of concentrate was consumed $3 \mathrm{~d}$ in a row (successful intake; $\mathrm{n}=8$ ), or they were $42 \mathrm{~d}$ of age (failed intake; $\mathrm{n}=6$ ). All calves except one met all subsequent targets. Once this goal was reached, milk allowance was decreased by $25 \%$ of the average milk intake for the previous 3 d. Once the calf ate 675 $\mathrm{g}$ for 3 consecutive days, milk was once again reduced by $25 \%$ of the previous 3 -d average. Calves received this final milk allowance until 1,300 $\mathrm{g}$ of concentrate was consumed $3 \mathrm{~d}$ in a row, at which point all milk was removed.

${ }^{2}$ All calves were offered $12 \mathrm{~L} / \mathrm{d}$ of milk until d 30, and then milk allowance was reduced to $75 \%$ of the calf's average milk intake over the previous $3 \mathrm{~d}(\mathrm{n}=28)$. Calves weaned by age $(\mathrm{n}=14)$ experienced a gradual reduction in milk (by $0.5 \pm 0.1 \mathrm{~L} / \mathrm{d})$ from $\mathrm{d} 42$ to 56 , so that they were fully weaned by $\mathrm{d} 56$.

${ }^{3}$ Calculated as the average of the previous $3 \mathrm{~d}$, with the requirement that each of the $3 \mathrm{~d}$ met at least $50 \%$ of the target.

${ }^{4}$ Unrewarded refers to a visit where milk was not available. 
intake $\left(t_{2,11}=2.07, P=0.06\right)$ and failed-intake $\left(t_{2,11}=\right.$ $1.78, P=0.10)$ calves tended to consume less milk per day than calves weaned by age.

Concentrate intake differed between weaning methods for each of the experimental periods, except during postweaning $\left(F_{2,5}=0.56, P=0.60\right.$; Figure 1). During preweaning, failed-intake calves consumed less concen- trate per day than successful-intake calves $\left(t_{2,8}=2.93\right.$, $P=0.02)$ and tended to also consume less concentrate per day than calves weaned by age $\left(t_{2,8}=2.15, P=\right.$ $0.06)$. There were no differences between successfulintake calves and calves weaned by age $\left(t_{2,8}=1.41 \mathrm{P}=\right.$ $0.20)$ during preweaning. During weaning, successfulintake calves consumed more concentrates per day

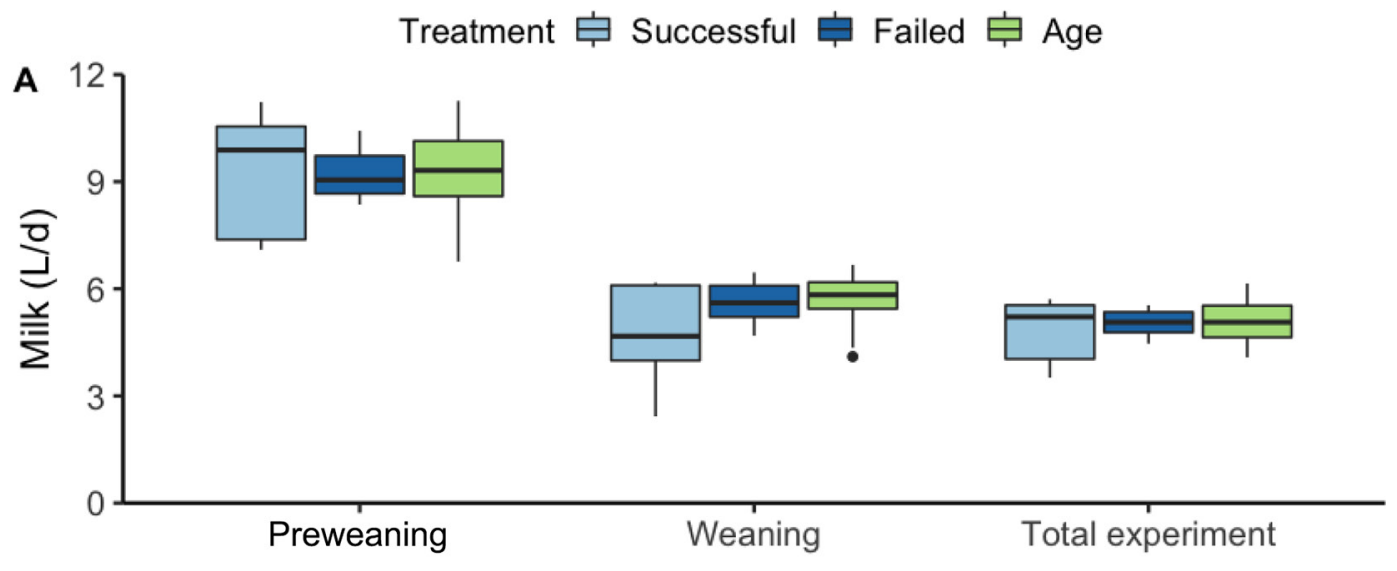

B
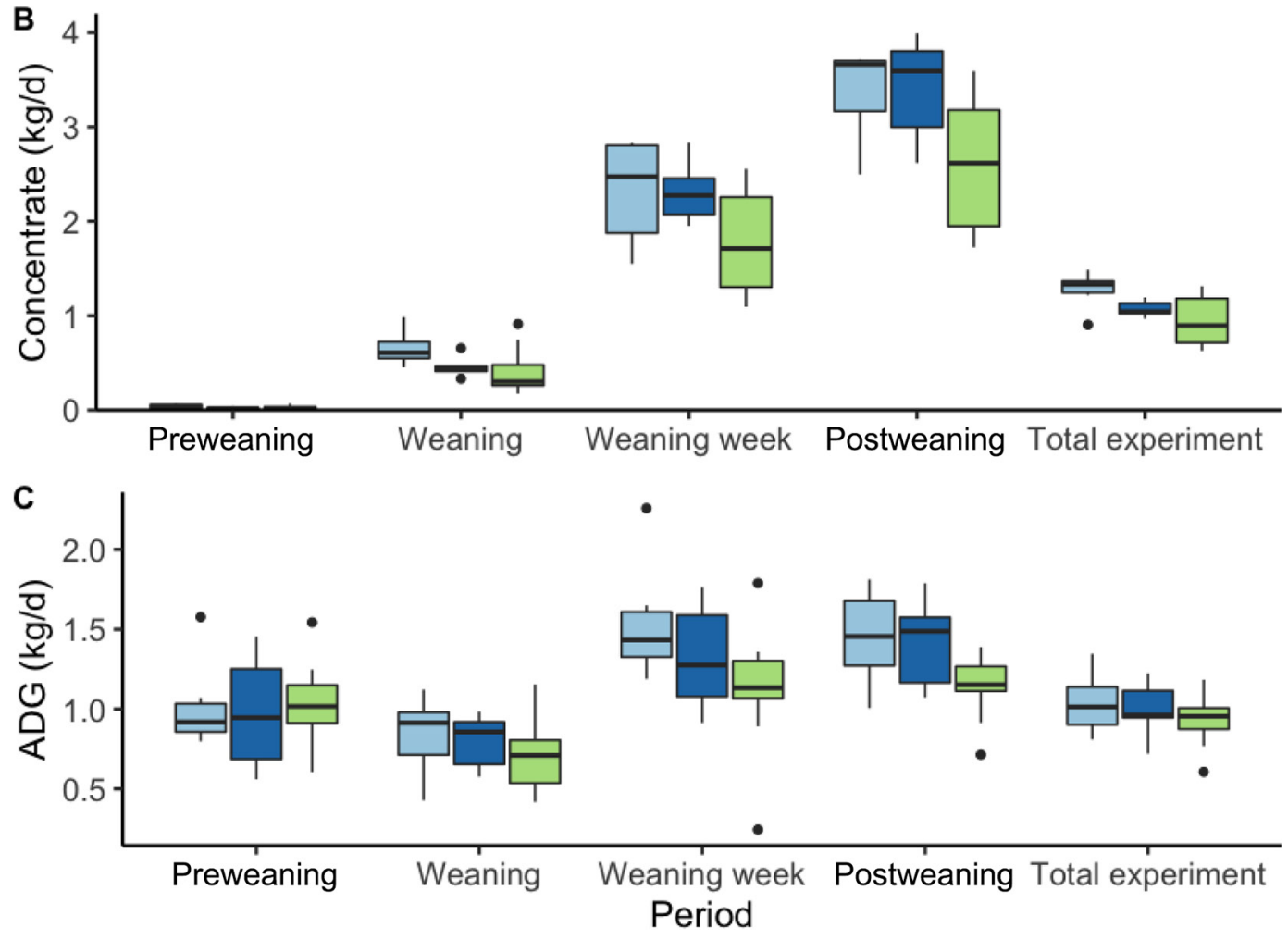

Figure 1. Arithmetic means $( \pm \mathrm{SD})$ for descriptive purposes of $(\mathrm{A})$ milk intake, $(\mathrm{B})$ concentrate intake, and $(\mathrm{C})$ ADG for Norwegian Red calves weaned based on age or concentrate intake (successful intake: $n=8$; failed intake: $n=6$; weaned by age: $n=14$ ) during each of 5 experimental periods: preweaning (full milk allowance; 10-30 d of age), weaning (milk allowance gradually reduced by method until completely weaned), weaning week ( $3 \mathrm{~d}$ before weaning and the first $7 \mathrm{~d}$ of $0 \mathrm{~L} / \mathrm{d}$ milk allowance), postweaning ( $20 \mathrm{~d}$ postweaning), and the total experimental period (d 10 to $20 \mathrm{~d}$ postweaning). Box plots show medians (horizontal line) and 25th and 75th percentiles (boundaries of the box or hinges; first and third quartiles). The upper whisker extends from the hinge to the largest value no further than 1.5 times the interquartile range. The lower whisker extends from the hinge to the smallest value at most 1.5 times the interquartile range. Data beyond the whiskers are outlying points, plotted individually. 
than calves weaned by age $\left(t_{2,11}=2.38, P=0.04\right)$, but concentrate intake per day was not different between failed-intake calves and successful-intake calves $\left(t_{2,11}=\right.$ $1.62, P=0.13)$ and calves weaned by age $\left(t_{2,11}=0.22\right.$, $P=0.83)$. Similarly, successful-intake calves tended to consume more concentrates per day than both the failed-intake $\left(t_{2,11}=1.97, P=0.07\right)$ and weaned-byage $\left(t_{2,11}=1.77, P=0.10\right)$ calves during the weaning week. Finally, across the total experiment, successfulintake calves tended to consume more concentrates per day than weaned-by-age calves $\left(t_{2,6}=2.29, P=0.06\right)$, whereas the failed-intake calves were not different from the successful-intake calves $\left(F_{2,6}=0.50, P=0.63\right)$ or the weaned-by-age calves $\left(F_{2,6}=1.09, P=0.32\right)$.

Feeding behavior measures in relation to weaning method are presented in Table 7. Milk drinking speed was not different between weaning methods (preweaning: $F_{2,12}=0.69, P=0.52$; weaning: $F_{2,9}=0.26, P=$ 0.78 ; weaning week: $F_{2,4}=0.62, P=0.58$; and total experiment: $\left.F_{2,9}=0.21, P=0.82\right)$. During preweaning, weaned-by-age calves had more unrewarded visits per day than failed-intake calves $\left(t_{2,9}=2.81, P=0.02\right)$ and tended to have more unrewarded visits per day than successful-intake calves $\left(t_{2,9}=2.02, P=0.07\right)$. During weaning, failed-intake calves tended to have over double the unrewarded visits per day of both successful-intake $\left(t_{2,4}=2.05, P=0.11\right)$ and weaned-by-age calves $\left(t_{2,4}\right.$ $=2.22, P=0.09)$. Unrewarded visits per day were not different between weaning methods during the weaning week $\left(F_{2,9}=0.08, P=0.92\right)$ or total experiment $\left(F_{2,8}\right.$ $=0.39, P=0.69$ ).

\section{DISCUSSION}

To our knowledge, our study is the first to explore personality and feeding behavior around weaning in Norwegian Red calves, with a particular focus on sociability personality trait. Our study builds on previous work investigating the relationship between personality and feeding behavior and growth around weaning, and on work testing individualized methods to gradually wean dairy calves (Neave et al., 2018; Benetton et al., 2019; Neave et al., 2019). Our study used a similar weaning method to Benetton et al. (2019), based on individual intake of concentrate. One main difference between our studies was in how failed-intake calves were defined; Benetton et al. (2019) defined these calves based on failure to consume the final intake target of $1,300 \mathrm{~g}$ by $63 \mathrm{~d}$ of age (and thus were gradually weaned from d 63-70). In contrast, the calves in our study were labeled as failed-intake calves if they failed to consume the first intake target of $225 \mathrm{~g}$ by $42 \mathrm{~d}$ of age (all of these calves eventually reached subsequent intake targets).
Personality appeared to have played a role in the differences in feeding behavior and performance observed in our calves, similar to several recent studies in young cattle (Meagher et al., 2017; Neave et al., 2018, 2019). In our study, calves scoring high on factor 1 (playful/ exploratory) had higher preweaning milk intake, overall higher concentrate intakes, and faster milk drinking speed during the weaning week. Other studies have also found positive associations with growth and feed intake (especially concentrate intake) in calves that were more exploratory (Neave et al., 2018, 2019). Other studies found a relationship between exploration and willingness to try new feeds (Costa et al., 2014; Meagher et al., 2017; Costa et al., 2020). Willingness to try new feeds may allow animals to adjust their diet to reduce their risk of maladies and avoid satiety of a single food (Villalba et al., 2010), suggesting the value of exploration in feeding behaviors. Perhaps the playful/exploratory calves in our study were more willing to try the concentrate, and thus were able to transition from milk to concentrate without a growth check.

Calves scoring high on factor 2 (sociability vocal/ active trait) had lower preweaning milk intakes, lower overall concentrate intakes, and tended to have slower drinking speeds during weaning week. The relationship between vocalizations and activity identified by the PCA suggests this behavior combination may reflect calves that were especially affected by social isolation. Social species may frequently vocalize in novel environments to re-establish contact with their herd, suggesting vocalizations may be a measure of sociability (Van Reenen et al., 2005; Forkman et al., 2007; Villalba et al., 2009). Few studies have investigated how sociability is related to feeding behavior in young farm animals; one study found that lambs who vocalized more during a novel environment test (more reactive to social isolation) consumed less of a novel food (Villalba et al., 2009). In calves, a naturally gregarious species, social isolation in individual housing resulted in increased reactivity toward environmental novelty (Jensen et al., 1997; De Paula Vieira et al., 2012b) and novel feeds (Costa et al., 2014) and decreased intake of concentrate (De Paula Vieira et al., 2010; Costa et al., 2015) compared with calves that were socially housed soon after birth. The individual differences in response to social isolation seen in our novelty tests may demonstrate an aspect of a sociability personality trait that has associations with reduced milk and concentrate intake during the calves' first weeks of life.

In our study, group-housed calves were tested in isolation without visual contact with other calves during the novelty tests, a situation they may rarely experience once group housed on dairy farms. Some authors have argued that tests in artificial environments may 
not accurately reflect natural behavior (Biro, 2013; Carter et al., 2013), and behaviors in isolation may be difficult to interpret for herd animals (Forkman et al., 2007). Some work has related behaviors in individual tests to behaviors expressed in group situations in adult cattle (Gibbons et al., 2010; Foris et al., 2018), but little is known for calves. The group novel object test used in this study, where individuals encountered novelty together with other herd members, was designed to reflect a more realistic novel situation that calves may experience on farm during management changes. Similar to factor 2 (sociability vocal/active in the individual test), calves scoring high on factor 3 (sociability interactive in group test trait) had lower concentrate intakes during preweaning and weaning. This personality trait may represent those calves that respond differently toward novelty in a stable social environment, reflecting a different aspect of a sociability trait than factor 2 scored in the individual test. Taken together, the similar associations of factor 2 (vocal/active) and factor 3 (interactive in group test) with reduced feed intake suggested that different aspects of sociability can affect feeding behavior of young calves.

The negative association of sociability with feed intake was not aligned with our predictions. Several studies have found that socially-housed calves begin to consume concentrates sooner and consume more concentrates than individually housed calves (Babu et al., 2004; De Paula Vieira et al., 2010; Costa et al., 2015), possibly because social models can encourage feeding behavior (De Paula Vieira et al., 2012a; Costa et al., 2016; Arrazola et al., 2020). The lack of a positive relationship between sociability and feed intake in the current study may have been due to a feeder design that prevented feeding with a partner. In natural systems, herds of cattle are known to graze together (Dwyer, 1961; Reinhardt and Reinhardt, 1981; Vitale et al., 1986), and one study found that more social cows (measured as latency to reunite with the herd along a runway, similar to the social motivation test in this study) were also more synchronized with herd mates and were present at the feeder during peak feeding times (Gibbons et al., 2010). The calves in our study were only able to access the milk and concentrate feeders one at a time, which may have limited feeding synchrony or even led to competitive interactions when calves were hungry at the same time (De Paula Vieira et al., 2008). However, the calves in our study were able to eat hay and silage at the same time. Though we were unable to capture the forage feeding behavior, perhaps the more sociable calves were socially consuming hay and silage to supplement their concentrate intake.

A second explanation for the negative relationship between sociability and feed intake may be that our personality tests did not identify calves that are adept to "social learn" in a feeding environment, such that an animal observes others to efficiently acquire food location or develop feeding behaviors (Launchbaugh and Howery, 2005). We interpreted aspects of sociability of calves to be their response to isolation (vocal/active) and most comfortable with others (interactive in group test), but perhaps these traits are unrelated to degree of social learning. Indeed, personality may affect use of information (Kurvers et al., 2010) and differences in learning such that bolder animals show improvements in solving a task after watching a demonstrator (Marchetti and Drent, 2000; Carter et al., 2014). For example, chacma baboons (Papio ursinus) that were bolder (i.e., spent more time inspecting a novel food) showed greater improvements in solving a task after watching a demonstrator (Carter et al., 2014). There has been some work exploring individual differences in learning in calves; one study found that more active calves (or a proactive coping style) tended to be less persistent when learning to push panels for a food reward (Webb et al., 2015). Future studies may consider individual differences in social learning in calves to improve management, especially when calves are learning about different foods during weaning.

Although we did not find an interaction between personality effects and weaning method, we did find differences due to weaning method. Calves who successfully weaned based on concentrate intake (i.e., consumed the first concentrate target of $225 \mathrm{~g}$ by $42 \mathrm{~d}$ of age) had higher ADG during the weaning week and postweaning compared with calves that failed to reach this first concentrate target or calves that were weaned based on age. The higher growth in calves weaned by concentrate was likely due to greater overall concentrate intake during the study period. These results support those of Benetton et al., (2019), who also weaned calves based on concentrate intake or based on age. Calves who begin consuming concentrates earlier appear to continue to consume high amounts of concentrates during their first 3 mo of life, which may improve growth as they transition between liquid and solid feed diets.

The differences we observed in growth between the successful-intake and weaned-by-age calves may be because only 3 of the 14 calves weaned by age were consuming the final concentrate target of $1,300 \mathrm{~g} / \mathrm{d}$ at the time they were weaned at $56 \mathrm{~d}$ of age. The Bovine Alliance on Management and Nutrition (2017) recommends that calves consume $1,300 \mathrm{~g} / \mathrm{d}$ of concentrates before weaning; therefore, our results suggested weaning at $56 \mathrm{~d}$ of age is too early for many calves. Similarly, de Passillé and Rushen (2016) found that early-weaned (48 d of age) Holstein calves consumed less concentrates during weaning and had lower ADG than calves 
weaned by concentrate intake (weaning began when calves consumed $200 \mathrm{~g} / \mathrm{d}$ and concluded when calves consumed 1,400 g/d). Premature weaning from high milk allowance can compromise growth (Sweeney et al., 2010), which may explain why our weaned-by-age calves and the early-weaned calves in de Passillé and Rushen (2016) had lower ADG than calves who successfully weaned by intake. Weaning based on intake requires each calf to consume target levels of concentrate before milk allowances are reduced.

We also found differences in milk intake between weaning methods over the total experiment, particularly during weaning, where successful-intake calves consumed less milk per day than calves weaned by age. This result supports both de Passillé and Rushen (2016) and Benetton et al. (2019), who showed that weaning by concentrate intake can decrease the amount of milk consumed across the milk feeding period, especially for calves who successfully begin eating concentrates. Our study used a step-down weaning method (milk was first reduced for all calves at $30 \mathrm{~d}$ of age) to gradually wean calves from high milk allowances, similar to Benetton et al. (2019). Calves weaned by this type of step-down method not only experience improved growth (Khan et al., 2007b) and rumen development (Khan et al., 2007a) compared with calves abruptly weaned, but when a step-down in milk allowance is combined with weaning by intake, these calves may also consume less overall milk. Gradually weaning by intake may allow farms to encourage an earlier transition from milk to concentrates for calves who are able to quickly reach concentrate targets.

Calves wean at variable ages in semi-natural systems (Reinhardt et al., 1978; Reinhardt and Reinhardt, 1981; Veissier et al., 1990). Thus, it is not surprising that calves will also wean at variable ages when weaned based on individual intakes, as we observed in the current study (weaned 46-84 d of age) and has been previously reported (45-98 d of age: Roth et al., 2009; 58-94 d of age: de Passillé and Rushen, 2016; 40-62 d of age: Benetton et al., 2019). Interestingly, these differences begin to arise in the first month of life. Calves were all managed the same way in the first $30 \mathrm{~d}$ before weaning methods were applied, yet failedintake calves consumed less milk per day (compared with weaned-by-age calves) and did not begin eating concentrates in their first month of age, unlike calves in successful-intake and weaned-by-age methods who were consuming $40 \mathrm{~g}$ of concentrate within the first $30 \mathrm{~d}$ of life. Benetton et al. (2019) described a similar pattern, where failed-intake calves consumed less concentrates during their first month of life than successful-intake calves. Furthermore, we found that once calves began the weaning period, failed-intake calves tended to have more unrewarded visits to the milk feeder than successful-intake and weaned-by-age calves, which may be indicative of hunger (De Paula Vieira et al., 2008; Rosenberger et al., 2017). These failed-intake calves, who experienced a forced step-down in milk allowance at $42 \mathrm{~d}$ of age, may not have been prepared to begin relying on concentrates and were likely still hungry for milk during the weaning period. Alternatively, the failed-intake calves may have been more neophobic of the concentrates (Costa et al., 2014); early hesitancy to eat concentrates may have led to failure to meet the first concentrate target and a later weaning age than successful-intake calves. These findings together suggest that failed-intake calves may need a longer period with milk; early identification of failed-intake calves (which could be done within the first $30 \mathrm{~d}$ ) may allow farms to allocate more milk to these calves and delay their weaning to ensure that they successfully transition to a solid feed diet at a pace that does not affect growth during the weaning transition. For example, farms may be able to offer different gradual weaning regimens for those calves who have or have not started to eat concentrates by 1 mo of age.

Although personality and weaning method play a role in the feeding behavior and growth of Norwegian Red calves, there may be other causes of individual variation. Calves in our study experienced a high incidence of diarrhea. The results of our study should be viewed with some caution as most of the calves experienced diarrhea at some point during the study period. This poor health may have negatively affected their daily feeding behavior (Belaid et al., 2020) and growth (Knauer et al., 2017), as well as their activity (Hart, 1988) and willingness to explore during the personality tests. However, no calves showed clinical signs of sickness when participating in the personality tests. We did not have the statistical power to draw inferences between the sick and healthy animals in this study, but we did statistically control for sickness in the models. Also, our small sample of failed-intake calves likely limited our ability to detect differences in some behaviors. Finally, it is possible that some failed-intake calves could have been consuming higher amounts of roughage (i.e., hay or silage that was offered ad libitum) instead of concentrates, given that calves show variation in their dietary preferences (Webb et al., 2014). However, we were unable to measure the intakes of these roughages. Future studies might consider using roughage intake in addition to concentrate intake to determine appropriate weaning steps for different calves. 


\section{CONCLUSIONS}

Personality traits, particularly sociability and exploration, affected the feeding behavior in Norwegian Red calves; calves that were more playful/exploratory consumed more milk and concentrates, and calves expressing sociability traits (vocal/active and interactive in group test) ate less concentrates. These associations did not vary with weaning method. Overall, weaning by concentrate intake ensures that calves are consuming recommended amounts of concentrate before weaning. Gradually weaning by individual concentrate intakes provides an opportunity for calves to wean at a pace that fits each individual calf.

\section{ACKNOWLEDGMENTS}

The authors thank the staff at the Livestock Production Research Centre (SHF) at the Norwegian University of Life Sciences (NMBU; Ås, Norway), especially Ida Charlotte Hjelmeset, for care of the calves. We thank our colleagues at the University of British Columbia Animal Welfare Program (Vancouver, Canada) for their support, especially Marina von Keyserlingk, Daniel Weary, and Benjamin Lecorps. Funding for LW was provided by the University of British Columbia Four-Year Doctoral Fellowship (Vancouver, Canada). Funding for this project is from the Norwegian Research Funding for Agriculture and the Food Industry (MATFONDAVTALE; The Research Council of Norway): Project 268023, Quality Calf. The authors have not stated any conflicts of interest.

\section{REFERENCES}

Arrazola, A., K. Dicker, E. Vasseur, and R. Bergeron. 2020. The effect of early housing and companion experience on the grazing and ruminating behaviour of naïve heifers on pasture. Appl. Anim. Behav. Sci. 226:104993. https://doi.org/10.1016/j.applanim.2020 104993.

Babu, L. K., H. N. Pandey, and A. Sahoo. 2004. Effect of individual versus group rearing on ethological and physiological responses of crossbred calves. Appl. Anim. Behav. Sci. 87:177-191. https://doi .org/10.1016/j.applanim.2004.01.006.

Belaid, M. A., M. Rodríguez-Prado, D. V. Rodríguez-Prado, E. Chevaux, and S. Calsamiglia. 2020. Using behavior as an early predictor of sickness in veal calves. J. Dairy Sci. 103:1874-1883. https:// doi.org/10.3168/jds.2019-16887.

Benetton, J. B., H. W. Neave, J. H. C. Costa, M. A. G. von Keyserlingk, and D. M. Weary. 2019. Automatic weaning based on individual solid feed intake: Effects on behavior and performance of dairy calves. J. Dairy Sci. 102:5475-5491. https://doi.org/10 3168/jds.2018-15830.

Biro, P. A. 2013. On the use of rapid assays in personality research: A response to Edwards et al. Anim. Behav. 86:e1-e3. https://doi .org/10.1016/j.anbehav.2013.04.020.

Borderas, T. F., A. M. B. de Passillé, and J. Rushen. 2009. Feeding behavior of calves fed small or large amounts of milk. J. Dairy Sci. 92:2843-2852. https://doi.org/10.3168/jds.2008-1886.
Bovine Alliance on Management and Nutrition. 2017. A Guide to Feeding and Weaning Healthy and Productive Dairy Calves. Accessed Jan. 5, 2021. https://www.aphis.usda.gov/animal_health/ nahms/dairy/downloads/bamn/BAMN17_GuideFeeding.pdf.

Carter, A. J., W. E. Feeney, H. H. Marshall, G. Cowlishaw, and R. Heinsohn. 2013. Animal personality: What are behavioural ecologists measuring? Biol. Rev. Camb. Philos. Soc. 88:465-475. https: //doi.org/10.1111/brv.12007.

Carter, A. J., H. H. Marshall, R. Heinsohn, and G. Cowlishaw. 2014 Personality predicts the propensity for social learning in a wild primate. PeerJ 2:e283. https://doi.org/10.7717/peerj.283.

Costa, J. H. C., W. G. Costa, D. M. Weary, L. C. P. Machado Filho , and M. A. G. von Keyserlingk. 2016. Dairy heifers benefit from the presence of an experienced companion when learning how to graze. J. Dairy Sci. 99:562-568. https://doi.org/10.3168/jds.2015-9387.

Costa, J. H. C., R. R. Daros, M. A. G. von Keyserlingk, and D. M. Weary. 2014. Complex social housing reduces food neophobia in dairy calves. J. Dairy Sci. 97:7804-7810. https://doi.org/10.3168/ jds.2014-8392

Costa, J. H. C., R. K. Meagher, M. A. G. von Keyserlingk, and D. M. Weary. 2015. Early pair housing increases solid feed intake and weight gains in dairy calves. J. Dairy Sci. 98:6381-6386. https:// doi.org/10.3168/jds.2015-9395.

Costa, J. H. C., H. W. Neave, D. M. Weary, and M. A. G. von Keyserlingk. 2020. Use of a food neophobia test to characterize personality traits of dairy calves. Sci. Rep. 10:7111. https://doi.org/ 10.1038/s41598-020-63930-8.

de Passillé, A. M., and J. Rushen. 2016. Using automated feeders to wean calves fed large amounts of milk according to their ability to eat solid feed. J. Dairy Sci. 99:3578-3583. https://doi.org/10 $.3168 /$ jds.2015-10259.

De Paula Vieira, A., A. M. de Passillé, and D. M. Weary. 2012b. Effects of the early social environment on behavioral responses of dairy calves to novel events. J. Dairy Sci. 95:5149-5155. https:// doi.org/10.3168/jds.2011-5073.

De Paula Vieira, A., V. Guesdon, A. M. de Passillé, M. A. G. von Keyserlingk, and D. M. Weary. 2008. Behavioural indicators of hunger in dairy calves. Appl. Anim. Behav. Sci. 109:180-189. https://doi .org/10.1016/j.applanim.2007.03.006.

De Paula Vieira, A., M. A. G. von Keyserlingk, and D. M. Weary 2010. Effects of pair versus single housing on performance and behavior of dairy calves before and after weaning from milk. J. Dairy Sci. 93:3079-3085. https://doi.org/10.3168/jds.2009-2516.

De Paula Vieira, A., M. A. G. von Keyserlingk, and D. M. Weary. 2012a. Presence of an older weaned companion influences feeding behavior and improves performance of dairy calves before and after weaning from milk. J. Dairy Sci. 95:3218-3224. https://doi .org/10.3168/jds.2011-4821.

Dwyer, D.D. 1961. Activities and grazing preferences of cows with calves in northern Osage Country, Oklahoma. Bull. Oklahoma Agric. Exp. Stn. B-588.

Enríquez, D., M. J. Hötzel, and R. Ungerfeld. 2011. Minimising the stress of weaning of beef calves: a review. Acta Vet. Scand. 53:28. https://doi.org/10.1186/1751-0147-53-28.

Fecteau, G., J. Paré, D. C. Van Metre, B. P. Smith, C. A. Holmberg, W. Guterbock, and S. Jang. 1997. Use of a clinical sepsis score for predicting bacteremia in neonatal dairy calves on a calf rearing farm. Can. Vet. J. 38:101-104.

Foris, B., M. Zebunke, J. Langbein, and N. Melzer. 2018. Evaluating the temporal and situational consistency of personality traits in adult dairy cattle. PLoS One 13:e0204619. https://doi.org/10 .1371/journal.pone.0204619.

Forkman, B., A. Boissy, M.-C. Meunier-Salaün, E. Canali, and R. B. Jones. 2007. A critical review of fear tests used on cattle, pigs, sheep, poultry and horses. Physiol. Behav. 92:340-374. https://doi .org/10.1016/j.physbeh.2007.03.016.

Fraser, D., D. Weary, E. A. Pajor, and B. N. Milligan. 1997. A scientific conception of animal welfare that reflects ethical concerns. Anim. Welf. 6:187-205.

Friard, O., and M. Gamba. 2016. BORIS: a free, versatile open-source event-logging software for video/audio coding and live observa- 
tions. Methods Ecol. Evol. 7:1325-1330. https://doi.org/10.1111/ 2041-210X.12584.

Gibbons, J. M., A. B. Lawrence, and M. J. Haskell. 2010. Measuring sociability in dairy cows. Appl. Anim. Behav. Sci. 122:84-91. https://doi.org/10.1016/j.applanim.2009.11.011.

Hart, B. L. 1988. Biological basis of the behavior of sick animals. Neurosci. Biobehav. Rev. 12:123-137. https://doi.org/10.1016/S0149 -7634(88)80004-6.

Hedlund, L., and H. Løvlie. 2015. Personality and production: Nervous cows produce less milk. J. Dairy Sci. 98:5819-5828. https://doi .org $/ 10.3168 / j d s .2014-8667$.

Hutchison, H. G., R. Woof, R. M. Mabon, I. Salehe, and J. M. Robb. 1962. A study of the habits of zebu cattle in Tanganyika. J. Agric. Sci. 59:301-317. https://doi.org/10.1017/S0021859600015379.

Jensen, M. B., K. S. Vestergaard, C. C. Krohn, and L. Munksgaard. 1997. Effect of single versus group housing and space allowance on responses of calves during open-field tests. Appl. Anim. Behav. Sci. 54:109-121. https://doi.org/10.1016/S0168-1591(96)01183-5.

Kassambara, A. 2020. ggpubr: "ggplot2" based publication ready plots. $\mathrm{R}$ package version 0.4.0. Accessed March 5, 2021. https:/CRAN .R-project.org $/$ package $=$ ggpubr.

Khan, M. A., H. J. Lee, W. S. Lee, H. S. Kim, K. S. Ki, T. Y. Hur, G. H. Suh, S. J. Kang, and Y. J. Choi. 2007a. Structural growth, rumen development, and metabolic and immune responses of Holstein male calves fed milk through step-down and conventional methods. J. Dairy Sci. 90:3376-3387. https://doi.org/10.3168/jds .2007-0104.

Khan, M. A., H. J. Lee, W. S. Lee, H. S. Kim, S. B. Kim, K. S. Ki, J. K. Ha, H. G. Lee, and Y. J. Choi. 2007b. Pre- and postweaning performance of Holstein female calves fed milk through step-down and conventional methods. J. Dairy Sci. 90:876-885. https://doi .org/10.3168/jds.S0022-0302(07)71571-0.

Knauer, W. A., S. M. Godden, A. Dietrich, and R. E. James. 2017. The association between daily average feeding behaviors and morbidity in automatically fed group-housed preweaned dairy calves. J. Dairy Sci. 100:5642-5652. https://doi.org/10.3168/jds.2016-12372.

Koolhaas, J. M., S. M. Korte, S. F. De Boer, B. J. Van Der Vegt, C. G. Van Reenen, H. Hopster, I. C. De Jong, M. A. W. Ruis, and H. J. Blokhuis. 1999. Coping styles in animals: Current status in behavior and stress- physiology. Neurosci. Biobehav. Rev. 23:925-935. https://doi.org/10.1016/S0149-7634(99)00026-3.

Kour, H., N. J. Corbet, K. P. Patison, and D. L. Swain. 2021. Changes in the suckling behaviour of beef calves at 1 month and 4 months of age and effect on cow production variables. Appl. Anim. Behav. Sci. 236:105219. https://doi.org/10.1016/j.applanim.2021.105219.

Krause, J., R. James, and D. P. Croft. 2010. Personality in the context of social networks. Philos. Trans. R. Soc. Lond. B Biol. Sci. 365:4099-4106. https://doi.org/10.1098/rstb.2010.0216.

Kurvers, R. H. J. M., K. van Oers, B. A. Nolet, R. M. Jonker, S. E. van Wieren, H. H. T. Prins, and R. C. Ydenberg. 2010. Personality predicts the use of social information. Ecol. Lett. 13:829-837. https://doi.org/10.1111/j.1461-0248.2010.01473.x.

Launchbaugh, K. L., and L. D. Howery. 2005. Understanding landscape use patterns of livestock as a consequence of foraging behavior. Rangeland Ecol. Manag. 58:99-108. https://doi.org/10.2111/ 03-146.1.

Lecorps, B., D. M. Weary, and M. A. G. Von Keyserlingk. 2018. Pessimism and fearfulness in dairy calves. Sci. Rep. 8:1421. https:// doi.org/10.1038/s41598-017-17214-3.

Marchetti, C., and P. J. Drent. 2000. Individual differences in the use of social information in foraging by captive great tits. Anim. Behav. 60:131-140. https://doi.org/10.1006/anbe.2000.1443.

McGuirk, S. M. 2008. Disease management of dairy calves and heifers. Vet. Clin. North Am. Food Anim. Pract. 24:139-153. https://doi .org/10.1016/j.cvfa.2007.10.003.

McGuirk, S. M., and S. F. Peek. 2014. Timely diagnosis of dairy calf respiratory disease using a standardized scoring system. Anim. Health Res. Rev. 15:145-147. https://doi.org/10.1017/ S1466252314000267.

Meagher, R. K., D. M. Weary, and M. A. G. von Keyserlingk. 2017. Some like it varied: Individual differences in preference for feed variety in dairy heifers. Appl. Anim. Behav. Sci. 195:8-14. https:/ /doi.org/10.1016/j.applanim.2017.06.006.

Medrano-Galarza, C., S. J. LeBlanc, T. J. DeVries, A. Jones-Bitton, J. Rushen, A. Marie de Passillé, and D. B. Haley. 2017. A survey of dairy calf management practices among farms using manual and automated milk feeding systems in Canada. J. Dairy Sci. 100:6872-6884. https://doi.org/10.3168/jds.2016-12273.

Neave, H. W., J. H. C. Costa, J. B. Benetton, D. M. Weary, and M. A. G. von Keyserlingk. 2019. Individual characteristics in early life relate to variability in weaning age, feeding behavior, and weight gain of dairy calves automatically weaned based on solid feed intake. J. Dairy Sci. 102:10250-10265. https://doi.org/10.3168/jds 2019-16438.

Neave, H. W., J. H. C. Costa, D. M. Weary, and M. A. G. von Keyserlingk. 2018. Personality is associated with feeding behavior and performance in dairy calves. J. Dairy Sci. 101:7437-7449. https:// doi.org/10.3168/jds.2017-14248.

Ooms, J. 2020. writexl: Export data frames to Excel "xlsx" format.

Perals, D., A. S. Griffin, I. Bartomeus, and D. Sol. 2017. Revisiting the open-field test: What does it really tell us about animal personality? Anim. Behav. 123:69-79. https://doi.org/10.1016/j.anbehav 2016.10.006.

Réale, D., S. M. Reader, D. Sol, P. T. McDougall, and N. J. Dingemanse. 2007. Integrating animal temperament within ecology and evolution. Biol. Rev. Camb. Philos. Soc. 82:291-318. https://doi .org/10.1111/j.1469-185X.2007.00010.x.

Reinhardt, V., F. M. Mutiso, and A. Reinhardt. 1978. Social behaviour and social relationships between female and male prepubertal bovine calves (Bos indicus). Appl. Anim. Ethol. 4:43-54. https:// doi.org/10.1016/0304-3762(78)90092-5.

Reinhardt, V., and A. Reinhardt. 1981. Natural sucking performance and age of weaning in zebu cattle (Bos indicus). J. Agric. Sci. 96:309-312. https://doi.org/10.1017/S0021859600066089.

Renaud, D. L., T. F. Duffield, S. J. LeBlanc, D. B. Haley, and D. F. Kelton. 2018. Clinical and metabolic indicators associated with early mortality at a milk-fed veal facility: A prospective case-control study. J. Dairy Sci. 101:2669-2678. https://doi.org/10.3168/ jds.2017-14042.

Rosenberger, K., J. H. C. Costa, H. W. Neave, M. A. G. von Keyserlingk, and D. M. Weary. 2017. The effect of milk allowance on behavior and weight gains in dairy calves. J. Dairy Sci. 100:504-512. https://doi.org/10.3168/jds.2016-11195.

Roth, B. A., N. M. Keil, L. Gygax, and E. Hillmann. 2009. Influence of weaning method on health status and rumen development in dairy calves. J. Dairy Sci. 92:645-656. https://doi.org/10.3168/ jds.2008-1153.

Sibbald, A. M., H. W. Erhard, R. J. Hooper, B. Dumont, and A. Boissy. 2006. A test for measuring individual variation in how far grazing animals will move away from a social group to feed. Appl. Anim. Behav. Sci. 98:89-99. https://doi.org/10.1016/j.applanim .2005.08.015.

Sibbald, A. M., and R. J. Hooper. 2004. Sociability and the willingness of individual sheep to move away from their companions in order to graze. Appl. Anim. Behav. Sci. 86:51-62. https://doi.org/ 10.1016/j.applanim.2003.11.010.

Steine, G., D. Kristofersson, and A. G. Guttormsen. 2008. Economic evaluation of the breeding goal for Norwegian red dairy cattle. J. Dairy Sci. 91:418-426. https://doi.org/10.3168/jds.2006-747.

Sweeney, B. C., J. Rushen, D. M. Weary, and A. M. de Passillé. 2010. Duration of weaning, starter intake, and weight gain of dairy calves fed large amounts of milk. J. Dairy Sci. 93:148-152. https:/ /doi.org/10.3168/jds.2009-2427.

USDA. 2016. Dairy 2014: Dairy cattle management practices in the United States, 2014. Accessed Nov. 19, 2019. https://www.aphis .usda.gov/animal_health/nahms/dairy/downloads/dairy14/ Dairy14_dr_PartI_1.pdf.

Van Reenen, C. G., B. Engel, L. F. M. Ruis-Heutinck, J. T. N. Van Der Werf, W. G. Buist, R. B. Jones, and H. J. Blokhuis. 2004 Behavioural reactivity of heifer calves in potentially alarming test situations: A multivariate and correlational analysis. Appl. Anim. 
Behav. Sci. 85:11-30. https://doi.org/10.1016/j.applanim.2003.09 .007 .

Van Reenen, C. G., N. E. O'Connell, J. T. N. Van Der Werf, S. M. Korte, H. Hopster, R. B. Jones, and H. J. Blokhuis. 2005. Responses of calves to acute stress: Individual consistency and relations between behavioral and physiological measures. Physiol. Behav. 85:557-570. https://doi.org/10.1016/j.physbeh.2005.06.015.

Veissier, I., D. Lamy, and P. Le Neindre. 1990. Social behaviour in domestic beef cattle when yearling calves are left with the cows for the next calving. Appl. Anim. Behav. Sci. 27:193-200. https://doi .org/10.1016/0168-1591(90)90056-J.

Villalba, J. J., X. Manteca, and F. D. Provenza. 2009. Relationship between reluctance to eat novel foods and open-field behavior in sheep. Physiol. Behav. 96:276-281. https://doi.org/10.1016/j .physbeh.2008.10.010.

Villalba, J. J., F. D. Provenza, and X. Manteca. 2010. Links between ruminants' food preference and their welfare. Animal 4:1240-1247. https://doi.org/10.1017/S1751731110000467.

Vitale, A. F., M. Tenucci, M. Papini, and S. Lovari. 1986. Social behaviour of the calves of semi-wild Maremma cattle, Bos primigenius taurus. Appl. Anim. Behav. Sci. 16:217-231. https://doi.org/ 10.1016/0168-1591(86)90115-2.

Webb, L. E., B. Engel, H. Berends, C. G. van Reenen, W. J. J. Gerrits, I. J. M. de Boer, and E. A. M. Bokkers. 2014. What do calves choose to eat and how do preferences affect behaviour? Appl. Anim. Behav. Sci. 161:7-19. https://doi.org/10.1016/j.applanim 2014.09.016.
Webb, L. E., C. G. van Reenen, M. B. Jensen, O. Schmitt, and E. A. M. Bokkers. 2015. Does temperament affect learning in calves? Appl. Anim. Behav. Sci. 165:33-39. https://doi.org/10.1016/j .applanim.2015.01.013.

Wickham, H., M. Averick, J. Bryan, W. Chang, L. D'Agostino McGowan, R. François, G. Grolemund, A. Hayes, L. Henry, J. Hester, M. Kuhn, T. L. Pedersen, E. Miller, S. M. Bache, K. Müller, J. Ooms, D. Robinson, D. P. Seidel, V. Spinu, K. Takahashi, D. Vaughan, C. Wilke, K. Woo, and H. Yutani. 2019. Welcome to the tidyverse. J. Open Source Softw. 4:1686. https://doi.org/10.21105/ joss. 01686.

Wilson, D. J., J. Stojkov, D. L. Renaud, and D. Fraser. 2020. Short communication: Condition of male dairy calves at auction markets. J. Dairy Sci. 103:8530-8534. https://doi.org/10.3168/jds .2019-17860

\section{ORCIDS}

Laura Whalin () https://orcid.org/0000-0001-8710-4993

Heather W. Neave @ https://orcid.org/0000-0002-1818-8131

Julie Føske Johnsen ๑ https://orcid.org/0000-0001-5528-9663

Cecilie M. Mejdell @ https://orcid.org/0000-0002-1260-8502

Kristian Ellingsen-Dalskau $\odot$ https://orcid.org/0000-0003-1290-2485 